Blood gases give a little more problem but most of us are still bilingual.

The chief difficulty with this book for those who would wish to use it in clinical practice, rather than for examination purposes, is that it is necessary to know the contents well before knowing what to look for! An index would have helped greatly.

If you are prepared to learn the range and lay-out of the contents of this book, then there is much compact information given to jog the memory and this in a format which many people find acceptable. Unfortunately I do not find it useful in the practice of real live clinical medicine. It is well produced and reasonably priced.

D. J. WAYNE,

District General Hospital, Great Yarmouth NR31 6LA.

\section{The Physiology of Hemostasis}

By Derek Ogston. Pp. 378, illustrated. Croom Helm, London, Canberra, 1983. £19.95.

Amongst the several available multiauthor texts on haemostasis/ thrombosis, none is solely concerned with human physiology, and this book admirably meets a need. After an introductory chapter providing an overview of the subject for the non-specialist, the book is divided into two general parts. The first deals with the components of the haemostatic system, their interactions with each other and with other physiological defence mechanisms. The second covers the changes which accompany or are caused by physiological events, including the effects of nutritional and environmental factors, pregnancy and hormones. Disease states and the effects of drugs are not considered in any detail. The book will be a valuable source of reference to specialists in the field, particularly those engaged in clinical research, but is also strongly recommended to those whose main interests lie in other areas. Professor Ogston is to be congratulated for writing such an informative and very readable book.

\section{P. B. A. KeRNoFf,} Royal Free Hospital, London NW3 2QG.

\section{Reflections on the Universities and the National Health Service}

By SiR Fred Dainton. The Rock Carling Fellowship, 1981. Pp. xvii +165 . The Nuffield Provincial Hospitals Trust, London, 1983. f7.50.

A book from one of our leading scientist-statesmen on a topic of currently urgent concern to the Medical Schools is both welcome and timely. Sir Fred Dainton, a physical chemist with a distinguished research record, has been well placed to observe the University involvement in medical education, having been ViceChancellor in Nottingham during the establishment of the new Medical School there, as well as Chairman of the University Grants Committee, of the National Radiological Protection Board and of the Council of the Royal Postgraduate Medical School. His crisp judgments have won him the respect of our profession; his criticisms are penetrating but transparently well-intentioned. He sets out in this volume, which is based on a Rock Carling Lecture in 1981, to analyse the conflict between the Medical Schools and the Health Authorities which now all too often leaves the School at great disadvantage. It is a conflict now being faced in acute form in the London Teaching Districts, which find themselves unhappily in the situation of being RAWP losers but vital to the continued education of one-third of Britain's doctors. The background is comprehensively sketched in and Sir Fred's resume of the history of the involvement of the State in University education and in medical research is masterly. It shows all too clearly how an era of expansion and progress has been brought to an end during the last 4 years. However, the prescription for our ills is, perhaps inevitably, a little disappointing, almost suggesting 'Parturient montes, nascetur ridic lus mus'. It is proposed that a small change in the composition of the Authority in the Teaching Districts, giving greater weight to the University as opposed to the local council representation, woutd secure such a change in the climate of opinion that both DHSS arfe UGC would be better informed and therefore more likely to agrēe the UMT system for junior doctors could be abolished so that you graduates would be tempted into the pre-clinical departments, anf Professors would happily ignore the rewards of private practice. Perhaps there is no solution to the University/NHS conflict and ve must learn to live with it. Certainly, however, we shall not resolveit unless we recognise the increasing power of the Health Service managers, growing at the expense of the Authority membership, the role of the professional bodies both junior and senior in negotiating the terms of service for both NHS and Medical School staff, the current dependence of clinical academic departments upon privare practice, and the overriding importance of adequate Universi funding to maintain the position of the School in any bargain whic can be struck with the Health Authority.

D. INNES WILLIAMS, סे British Postgraduate Medical Federation, London WCIN 3EJ. ㅇำ

Smoking Control Strategies in Developing Countries. Report of W.H.O. Expert Committee

World Health Organization Technical Report Series 695. Pp. 92. World Health Organization, Geneva, 1983. Sw.fr. 8.00. (Availabls from HMSO, 49 High Holborn, London WC1V 6HB. Price 11.78 The third report of WHO on Smoking is concerned with its effect of developing countries. The committee was chaired by Dr A. RoAt Awadi the dynamic Minister of Health from Kuwait. Its task wogs $\overrightarrow{8 B}$ suggest strategies for governments and public health authoritis developing countries to combat the spread of smoking-re画ted diseases. Widespread smoking is considered a major stumbling to the successful achievement of WHO's goal of Health for All by this Year 2000. The Committee was alarmed that while smoking was some extent being brought under control in developed countrie developing countries are increasingly becoming targets for hight sophisticated and ruthless campaigns promoting smoking. Th international tobacco industry's irresponsible behaviour and massive advertising and promotional campaigns were considered be direct causes of a substantial number of unnecessary deaths. 3

The report documents growing evidence that tobacco use has already become a major source of disease in many developing countries where problems of malnutrition and infectious diseases are still prevalent. High death rates for lung cancer are reported from India, China, Hong Kong, Cuba and the Bantu in Natal. Coronany heart disease associated with cigarette smoking is a major problem India, Pakistan and the Phillipines. Perinatal mortality rates are doubled in Bangladeshi women who smoke. Even traditional form? of smoking such as Bidi or Hookah are hazardous and oral cancer frequent in Asian men and women who chew tobacco. Health for All by the year 2000 is likely to be a vain hope for the millions in developing countries who succumb to the blandishments of the tobacco companies.

This is a valuable document not only for those concerned with the health of developing countries but also for those ready to expose the activities of our own major tobacco companies who are increasing their promotional activities and exports to developing countries order to compensate for falling tobacco sales in the U.K. and othę industrialised countries.

K. P. BALL, $\underset{<}{0}$ Central Middlesex Hospital, London NW10 7NS. 